\title{
VIVÊNCIAS DE SOFRIMENTO MORAL NA PERCEPÇÃO DA EQUIPE CIRÚRGICA
}

\author{
Vanessa Torres Pereira'; Marluce Alves Nunes Oliveira ${ }^{2}$ \\ 1. Bolsista PIBIC/FAPESB, Graduando em Enfermagem, Universidade Estadual de Feira de Santana, \\ e-mail:fsavtp@hotmail.com \\ 2. Orientador, Departamento de Saúde, Universidade Estadual de Feira de Santana, e-mail: milicialves@yahoo.com.br
}

PALAVRAS-CHAVE: Sofrimento moral. Centro cirúrgico. Equipe cirúrgica.

\section{INTRODUÇÃO}

Ser ético é inerente ao ser humano, é uma condição fundamental para se viver em uma sociedade, embora a conjectura ética não seja compreendida por todas as pessoas. Assim, fazse necessário refletir acerca desse constructo para formação dos indivíduos, tanto no âmbito pessoal como no profissional (PEREIRA, 2016).

O Centro Cirúrgico (CC) se constitui em uma unidade hospitalar elegível para o desenvolvimento de intervenções cirúrgicas, bem como assistência a recuperação anestésica e ao pós-operatório imediato (BRASIL, 2002). Entendemos que os procedimentos cirúrgicos são desenvolvidos por uma equipe multiprofissional integrada e habilitada. Trata-se de um ambiente dotado de complexidade, onde os profissionais estão a todo tempo susceptíveis a situações conflituosas que envolvam aspectos éticos e morais (OLIVEIRA; SANTA ROSA, 2014).

Para Berger (2013, p. 395), o "Sofrimento moral é a dissonância cognitiva-emocional que surge quando se sente compelido a agir contra os próprios requisitos morais". Assim, o sofrimento moral decorre de situações em que o profissional se sente pressionado a agir de uma forma em que se entenda como eticamente errônea.

Percebemos que os efeitos biopsicossociais que podem ser consequências do sofrimento moral estão relacionados a tristeza, impotência, ira e frustração. De acordo com Bresolin e outros (2016), os profissionais podem ainda manifestar a introspecção, pelo fato de receberem pouco, ou nenhum, apoio que os condicionem a encarar os conflitos morais.

Considero importante abordar neste estudo sobre a equipe cirúrgica, pois está exposta a vivenciar o sofrimento moral. Ela é responsável por prestar o cuidado direto ao paciente que está sendo submetido a procedimento cirúrgico, por isso a mesma deve ser integrada e habilitada, a fim de que tudo transcorra com eficácia e eficiência. Essa equipe é formada pelos seguintes profissionais: anestesista, cirurgião, auxiliar de cirurgia, instrumentador, enfermeiro e técnico de enfermagem.

Assim, este estudo propõe com objetivo geral conhecer as vivências de sofrimento moral na percepção da equipe cirúrgica e como objetivos específicos descrever e refletir as vivências de sofrimento moral na percepção da equipe cirúrgica.

\section{METODOLOGIA}

Para Minayo (2011, p.14), a metodologia consiste no "caminho do pensamento e prática exercida na abordagem da realidade". A autora ressalta a importância das teorias, métodos e técnicas, bem como a criatividade e experiência do pesquisador como atributos indispensáveis para a investigação (MINAYO, 2010).

Trata-se de um estudo qualitativo, exploratório - descritivo. Tendo como objeto de estudo o sofrimento moral vivenciado pela equipe de enfermagem de CC.

O estudo foi desenvolvido na unidade de Centro Cirúrgico de um hospital filantrópico localizado no município de Feira de Santana-BA-Brasil. Os participantes da pesquisa foram 10 profissionais da equipe cirúrgica em atividade laboral por mais de um ano. 
As informações foram coletadas nos meses de novembro e dezembro de 2017, por meio de entrevista semiestruturada, que continham as seguintes questões norteadoras: Qual a sua compreensão sobre sofrimento moral? Fale-me de vivência de sofrimento moral em sua prática no Centro Cirúrgico. Qual a sua atitude diante de sofrimento moral em sua prática no Centro Cirúrgico?

Os dados empíricos foram tratados a partir do método de análise na modalidade estrutura do fenômeno situado, segundo a proposta de Martins e Bicudo (2005).

A análise em si se constituiu em Análise Ideográfica e Análise Nomotética (MARTINS; BICUDO, 2005).

$\mathrm{Na}$ análise dos relatos realizada com profissionais da equipe cirúrgica da unidade de Centro Cirúrgico emergiram três categorias: "Sofrimento moral no olhar da equipe cirúrgica", "Vivências de sofrimento moral pela equipe cirúrgica" e "Prevenção do Sofrimento Moral".

Este projeto de pesquisa está inserido no projeto VIVÊNCIAS DE CONFLITOS E DILEMAS ÉTICOS NA PERCEPÇÃO DA EQUIPE ENFERMAGEM NO CENTRO CIRÚRGICO. O projeto foi submetido ao Comitê de Ética em Pesquisa da Universidade Estadual de Feira de Santana, sob CAAE no 28656214.9.0000.0053.

Durante o desenvolvimento da pesquisa foram considerados os aspectos éticos que envolvem pesquisas com seres humanos, estabelecidos pela Resolução $n^{\circ} 466$ de 12 de dezembro de 2012, do Conselho Nacional de Saúde (CNS).

\section{ANÁLISE E DISCUSSÃO DOS RESULTADOS}

Dos 10 profissionais da equipe cirúrgica que participaram da pesquisa, 03 eram enfermeiros, 04 Técnicos de enfermagem e 03 médicos. Quanto ao sexo: 06 eram do sexo feminino e 04 do sexo masculino, o funcionário mais antigo atua em $\mathrm{CC}$ há 40 anos e a contratada mais recentemente possui um ano. Em relação ao vínculo empregatício, sete possuem outros vínculos.

\section{ANÁLISE IDEOGRÁFICA}

\section{CATEGORIA I - SOFRIMENTO MORAL NO OLHAR DA EQUIPE CIRÚRGICA}

Nesta categoria os depoimentos dos participantes do estudo revelam que o sofrimento moral quando conhecem, emerge em decorrência de carga horária extensa, dilemas cotidianos, falta de respeito para com os profissionais, situações que fogem ao controle, como coisas contrárias ao que considera como correto, além de sentimentos como a tristeza.

\section{CATEGORIA II- VIVÊNCIAS DE SOFRIMENTO MORAL PELA EQUIPE CIRÚRGICA}

Nesta categoria, os participantes desvelam que não vivenciaram e outros relatam que vivenciaram o sofrimento moral em sua prática laboral na unidade de Centro Cirúrgico. As vivências estão relacionadas a trabalhar com carga horária dobrada, conflitos entre os profissionais, a falta de recursos físicos e de recursos materiais.

\section{CATEGORIA III - PREVENÇÃO DO SOFRIMENTO MORAL}

Os depoimentos dos participantes do estudo revelam formas de prevenir o sofrimento moral, sendo elas através do respeito, postura ética e discussões em grupo.

\section{ANÁLISE NOMOTÉTICA}

Para realizar a análise nomotética faz-se necessário compreender e articular os relatos convergentes e divergentes, que poderão estar presentes nas categorias. 
Compreendemos o sofrimento moral como as ambiguidades que surgem quando o profissional sabe qual a forma correta a agir, porém não conseguem agir dessa forma, levando-os ao desencadeamento de sentimentos negativos como a angústia por não ter agido de forma assertiva ou o medo de ser penalizado pela ação.

O sofrimento moral decorre de situações onde existe falta de ética (TE03 e TE04). Para Figueiredo (2008), a ética conduz a pessoa nortear as suas ações, sendo essa primordial para a distinção entre as ações como boas (virtudes) ou más (vícios), a aquisição destes elementos pode ser segundo o conhecimento teórico e prático; sendo a ética adquirida devido ao pleno conhecimento teórico (resultante do ensino) e a moral segundo o conhecimento prático; os hábitos. Assim, cada pessoa possui sua própria ética, pois as experiências ou vivências irão nortear suas atitudes, tendo estas como bases o caráter e a personalidade singulares ao indivíduo.

A equipe cirúrgica refere ter vivenciado o sofrimento moral. A vivência de sofrimento moral em ambiente laboral inclui a carga horária extensiva que os técnicos de enfermagem são submetidos com caráter obrigatório, devido à ausência de recursos humanos (TE02 e TE04). Além disto, a ausência de recursos físicos e materiais culmina na existência de sofrimento moral (ME01 e ME02).

Os recursos humanos e financeiros são essenciais para o desempenho das atividades nas instituições de saúde, logo, deficiências desses recursos desencadeiam situações que fazem com que os profissionais usem artifícios, por exemplo, o improviso de materiais, de modo a sanar estas carências (PEREIRA, 2017).

As situações conflitantes propiciam a vivência de sofrimento moral (TE03 e E03). Para Oliveira e Santa Rosa (2016), o conflito é entendido como divergências de julgamentos, diante de uma mesma situação, aonde ambos não chegam a um consenso.

Faz-se necessário prevenir a iminência de sofrimento moral, o respeito é uma estratégia apontada pelos participantes para o enfrentamento. O respeito é importante para que situações que incidam em sofrimento moral não ocorram (TE01 e ME03).

Percebe-se que em algumas situações relatadas pelos participantes deste estudo, mostra sobre a forma grosseira em que são tratadas, seja advinda de pessoas que se sentem em posição de poder, e isto reflete as atitudes de desrespeito com os outros profissionais da equipe cirúrgica. Para Barlem (2013), o discurso dialógico relacionado como denúncia ao desrespeito ao profissional, ou ao sujeito, estabelece-se em exercício de poder.

Para Cardozo e Silva (2014), o relacionamento no ambiente de trabalho deve ser pautado em relação de confiança, empatia, respeito e harmonia. Assim, é possível favorecer um bom relacionamento interpessoal entre os trabalhadores evitando situações desagradáveis.

De acordo com Dalmolin e colaboradores (2012), estimular práticas de respeito entre os profissionais da equipe cirúrgica é importante para melhor assistência de saúde aos pacientes, além de benefícios no desempenho em ambiente laboral.

\section{CONSIDERAÇÕES FINAIS}

Esta investigação possibilitou conhecer as situações de sofrimento moral vivenciado na prática da equipe cirúrgica e que deve ser solucionado observando os preceitos éticos e legais da profissão.

O olhar dos participantes acerca do sofrimento moral diz respeito á carga horária extensa, dilemas cotidianos, falta de respeito para com os profissionais, situações que fogem ao controle, como coisas contrárias ao que considera como correto, além de sentimentos como a tristeza.

Os relatos dos participantes convergem ao relatarem suas vivências e divergem quanto aos participantes que não vivenciaram o sofrimento moral em sua prática laboral na 
unidade de Centro Cirúrgico. Estas vivências estão relacionadas as deficiências de recursos humanos, materiais e físicos e a falta de ética entre os profissionais.

Quanto ás estratégias de prevenção de sofrimento moral os profissionais revelam sendo elas através do respeito, postura ética e discussões em grupo.

Constatamos também que a equipe cirúrgica vivencia o sofrimento moral, portanto deve buscar fortalecer o relacionamento interpessoal dos profissionais, a fim de promover respeito no ambiente laboral além de viabilizar ações educativas para fortalecer o exercício ético, o estudo apontou a necessidade de um espaço para discussões e enfrentamentos das situações que ocasionam o sofrimento moral.

As facilidades encontradas para realização deste estudo consistiram no acesso a infraestrutura do Núcleo Interdisciplinar de Pesquisas e Estudos em Saúde (NIPES). As dificuldades incidiram na deficiência de artigos científicos sobre o tema, a rotina da equipe de enfermagem no centro cirúrgico que dificultou a realização das entrevistas.

A partir destes achados, outros estudos sobre esta temática devem ser realizados e divulgados, a fim de que a equipe cirúrgica reflita sobre as situações de sofrimento moral vivenciada no $\mathrm{CC}$ e saiba tomar decisões pautadas nos princípios éticos e legais da profissão.

\section{REFERÊNCIAS}

AMESTOY, S. C., et al. 2014. Gerenciamento de conflitos: desafios vivenciados pelos enfermeiros-líderes no ambiente hospitalar. Rev Gaúcha Enferm., v. 35, n. 2, p. 79-85.

BARLEM. E. L., Sofrimento moral em trabalhadores de enfermagem. Rev. Latino-Am. Enfermagem, Ribeirão Preto, v. 21 (esp) , p. 1 - 9, Jan - Fev, 2013.

BRASIL. Ministério da Saúde. Agência Nacional de Vigilância Sanitária. . 2002. RDC n50, de 21 de fevereiro de 2002. Dispõe sobre o Regulamento Técnico destinado ao planejamento, programação, elaboração, avaliação e aprovação de projetos físicos de estabelecimentos assistenciais de saúde. Diário Oficial da União, Poder Executivo, Brasília, DF.

CARDOZO, C. G.; SILVA, L. O. S. A importância do relacionamento interpessoal no ambiente de trabalho. Interbio v.8 n.2, Jul-Dez, 2014.

DALMOLIN, G. L., et. al. 2012. Implicações do sofrimento moral para os(as) enfermeiros(as) e aproximações com o burnout. Texto contexto enferm. Florianópolis, v. 21, n. 1, p. 200-208, jan - mar.

OLIVEIRA, M. A. N., SANTA ROSA, D. O. 2015. Conflitos e dilemas éticos vivenciados pelo enfermeiro no cuidado perioperatório. cienc cuid saúde. v. 14, n.2, p. 1156 - 1163.

MARTINS, J.; BICUDO, M. A. V. A pesquisa qualitativa em psicologia: fundamentos e recursos básicos. $5^{\text {a }}$ ed. São Paulo: Centauro: 2005.

MINAYO, M. C. S. 2010.O desafio do conhecimento: pesquisa qualitativa em saúde. 12. ed. São Paulo: Hucitec, p. 407.

MINAYO, M. C. S. 2011. Pesquisa social: teoria, método e criatividade. 30. ed. Petrópolis, RJ: Vozes, p. 108. 